\title{
The consequence of logistics development toward economy and local community (the case of Bangkok, Thailand)
}

\author{
Mahachai Sattayathamrongthian ${ }^{1, *}$ and Yingsak Vanpetch $^{2}$ \\ ${ }^{1}$ Rajamangala University of Technology Rattanakosin, Salaya, Nakhon Pathom, Thailand \\ ${ }^{2}$ Suan Sunandha Rajabhat University, Bangkok, Thailand
}

\begin{abstract}
This research was to define the Logistics Development Toward Economy and Local Community in the Urban Area around Bangkok Metropolitan, Thailand, Besides, observe the necessary planning, implementing, and monitoring.The appropriate analysis units are derived from the research questions and used to determine the data collection scope. Purposive sampling was used to select 28 Thai stakeholders and academics who influenced the planning, funding, construction, and monitoring of logistic infrastructure development in Thailand or those affected by logistic infrastructure in Thailand. The researchers designed semi-structured with open-ended questions. Besides, used in-depth interviewing and observation as instruments for data collection. Choosing 28 participants who understand road infrastructure planning, investments, construction, formulation, implementation, and monitoring of economic development strategies generated information-rich data, which was the study's primary goal.Kanchanapisek road project prompts economic and social change by making the network's association with the network, developing productsand ventures, incitement or speculation exercises, and the help of another foundation advancement example, schools, medical clinics. Transportation Foundation has, as of late, been credited for supporting different social administrations and giving admittance to schools, emergency clinics, and business places.Unfortunately, there are the issues disregarded, and hardly any endeavors have been made to decrease them. The policymakers should intercede to decrease every one of these effects and the methods for mediation that is generally attractive to create the most practical result in financial, social, and ecological terms.
\end{abstract}

\section{Introduction}

Logistics is a system of administrations that help develop products, exchange across fringes, and business inside the urban area. Coordination incorporates various exercises past transportation, including warehousing, financier, expedited service, and essential framework administrations, for example, terminals. Competing international networks of increasingly multiservice logistics providers offer more diversified solutions for trade,

\footnotetext{
* Corresponding authors: mahachai.sat@rmutr.ac.th
} 
commerce, and manufacturing ever. Many scholars have recognized logistics development as an essential economic growth facilitator and the essential key to economic development activities for many industrialized countries [1]. Many researchers have supported the relationship between Logistics Performance investments and a society's political, social, and economic development [2].

Bangkok Metropolitan region has congested with almost no metropolitan arranging or guideline. This has prompted the deficient framework and an indiscriminate design with slender streets, horrible traffic, and extreme air contamination. By 2030, Bangkok is expected to become one of the world's megacities with a population surpassing 10 million [3].

Kanchanaphisek Road [4], one of the tremendous logistic development, is an essential road with a ring road surrounding Bangkok city, through Nonthaburi province, Pathum Thani province, Samut Prakan province, Phra Nakhon Si Ayutthaya Province. The total distance is 168 kilometers. This road was created to solve traffic congestion in the Bangkok Metropolitan due to the increasing traffic and transportation volume resulting from economic growth. Construction started in 1978 during the Taling Chan-Bang Bua Thong period and completed all parts in 2007. There are two bridges across the Chao Phraya River, namely the Chiang Rak Bridge, Phra Nakhon Si Ayutthaya Province, and the Kanchanaphisek Bridge, Samut Prakan province.

Kanchanaphisek Road is the major road that connects the city around the Bangkok Metropolitan area due to its rise. Besides, significantly develop the logistic performance of the urban area. Furthermore, the BTS Sky Train purple line and the blue line project also connect with the Kanchanaphisek Road.This leads to improvements in mobility and standard of living for the masses.Transportation infrastructure investment has long been considered a subset or component of the capita, representing the necessary foundation that underpins all production functions.

According to the many literary works, logistics infrastructure investments are among the best apparent solutions to developing the urban area. In this research, the researchers focus on how the local people living in the urban area around Bangkok Metropolitan could benefit from it.

Research Questions

1. What is the impact of Logistics Development Toward Economy and Local Community in the Urban Area around Bangkok Metropolitan, Thailand

2. What is the necessary planning, implementing, and monitoring criteria needed for pre- and post-construction activities?

Research objectives

1. To define the Logistics Development Toward Economy and Local Community in the Urban Area around Bangkok Metropolitan, Thailand

2. To define the necessary planning, implementing, and monitoring criteria needed for pre- and post-construction activities?

\section{Literature Review}

Logistic development is part of economic development. In 1776, Adam Smith defined the vent-for-surplus condition as when a country or region produces more goods than it has consumers for, creating the need to transport the goods to other countries to vent surplus production capacity $[5,6]$ is inter-relations altogether determine the character of transportation with physical and social forces and conditions. It is a tool of the economic, political, military organizations, and the tool's character varies with their needs. The most permanent conditions of its progress are the natural obstacles it has to overcome and the natural forces it employs, but even these in their practical bearings are relative to social 
development [7,8]. Ramachandra, T., Rotimi cited several studies supporting the idea that infrastructure investments, specifically roads, lead to positive economic and social change for the poor $[9,10]$.

However, improving the transportation framework isn't sufficient to animate economic development in immature zones [11] the wealthy community would observe more linkage between the two than other low-middle income districts [12]. The economic advancement relies upon different components, including financial, political, regular geographic, verifiable, and segment. The economic improvement advantages of transportation interest in South Africa's High-Speed Rail venture named the "Gautrain." They cautioned that even though it facilitated gridlock and made positions, it likewise extended the versatility related prohibition and offered need to the rich in the circulation of public assets $[13,14]$.

Transportation planning stays from various perspectives, a specialized exercise described by examining money saving advantages, displaying, and technocratic dynamic. Simultaneously, the choices about the eventual fate of versatility will keep on sitting at the conversion of the market, government, and resident entertainers. Their different commitment to these dynamic spaces will be vivified by developing political orderings and vote based cycles.Transportation planning has been the focal point of some interest inside the pages of this diary as of late $[15,16]$. Presently, as urban areas get ready for a futurefocused on keen innovations, brilliant foundation, and shrewd urbanism.

\section{Research Methodology}

The appropriate analysis units are derived from the research questions and used to determine the data collection scope. Purposive sampling was used to select 28 Thai stakeholders and academics who influenced the planning, funding, construction, and monitoring of logistic infrastructure development in Thailand or those affected by logistic infrastructure in Thailand.

The researchers designed semi-structured with open-ended questions. Besides, usedindepth interviewing and observation as instruments for data collection. The interviews consisted of semi-structured open-ended questions. The interview questionnaire wasapproved by four expert panel members who had knowledge, experience, and understanding of logistic infrastructure investment and economic development. Interviews were conducted to gain detailed insights into participants' perspectives, opinions, and understanding of the subject being investigated [17].

Choosing 28 participants who understand road infrastructure planning, investments, construction, formulation, implementation, and monitoring of economic development strategies generated information-rich data, which was the study's primary goal. The specific procedures for how participants were identified, contacted, and recruited included the following criteria:

1) The government officials who had influenced logistic infrastructure development in any of the following capacities: planning, policy formulation, budgeting, construction, or performance monitoring and reporting.

2) The business stakeholders whose business success in Thailand and directly or indirectly affected by road infrastructure.

3) The academic who had observed logistic infrastructure development in any of the following capacities: planning, policy formulation, budgeting, construction, or performance monitoring and reporting.

Data analysis involves consolidating, reducing, and interpreting information from the interviews and observations. Content analysis involves interviews, participants' responses, observations, and field notes taken during interviews. The inductive analysis involves grouping participants' responses into categories and themes. 


\section{Research Result}

The demographic info of the research participants

Table 1. Demographic data of surveyed participants.

\begin{tabular}{|c|c|c|c|}
\hline \multicolumn{2}{|c|}{ Demographic } & Frequency & Percentage \\
\hline Gender & Male & 12 & 42.85 \\
\hline & Female & 16 & 57.15 \\
\hline Age & between 0-15 & 0 & 0 \\
\hline & between 16-30 & 5 & 17.85 \\
\hline & between 31-45 & 20 & 71.42 \\
\hline & between 46-60 & 2 & 7.14 \\
\hline Occupation & The government officials & 1 & 3.57 \\
\hline & The business stakeholders & 17 & 17.85 \\
\hline & The academic & 6 & 60.71 \\
\hline Homicide & Bangkok & 10 & 21.42 \\
\hline & Nonthaburi & 12 & 35.71 \\
\hline & Pathumthani & 6 & 42.85 \\
\hline & & & 21.42 \\
\hline
\end{tabular}

Most of the research participants are female, age between 31-45, business stakeholders, and live in Nonthaburi.

1. Define the Logistics Development Toward Economy and Local Community in the Urban Area around Bangkok Metropolitan, Thailand

1.1 The positive consequence of logistics performance on environmental quality, improvement of quality of life and individual mobility, and social quality.

Some participants have concurred that the framework ventures, explicitly road, lead to positive economic and social change for poor people. Foundation advancement is one of the primary determinants of long-haul economic development and gives individuals a stage to profit by the development cycle [18].

As indicated by REIC, the value file of empty land or land before improvement in Greater Bangkok in the second from last quarter was 256.5 focuses, rising $17 \%$ from a similar period a year ago.

A few participants have concurred about the positive connection between street and transportation foundation speculation and monetary turn events. A large portion of the land market costs fundamentally ascend after foundation speculation.

Kanchanapisek road project prompts economic and social change by making the network's association with the network, developing products and ventures, incitement or speculation exercises, and the help of another foundation advancement example, schools, medical clinics. Transportation Foundation has, as of late, been credited for supporting different social administrations and giving admittance to schools, emergency clinics, and business places. The Kanchanapisek street has assumed a massive part in how merchandise is moved across huge separations and how travelers are conveyed starting with one area then onto the next.

1.2 The negative consequence of logistics performance on environmental quality, improvement of quality of life and individual mobility, and social quality.

Some participants have concurred that the Kanchanapisek road promptly turned into the essential route for transportation or use as a detour of Bangkok, which fundamentally empowered and improved business and advancement, profiting local advancement over the scene. 
All participants agree that as assets are utilized to make wanted utilities, pollution is verifiably delivered as results during each coordinated chain measure flexibly. Putting resources into coordination's execution includes conveying and gathering merchandise and offering assistance in towns and urban areas. It likewise incorporates merchandise stockpiling and stock administration, squander taking care of, office and family unit expulsions, and home conveyance administrations. Because of their enormous populaces and broad business foundations, regions require vast amounts of products and ventures for business and homegrown use. The developing significance of transportation is identified with increments in metropolitan populaces and proceeded with economic development in metropolitan regions - this outcome in expanding levels of interest for cargo transport administrations.

Putting resources into coordination execution activities is answerable for a scope of adverse social and natural effects. The ecological effects are toxin outflows, including the essential ozone-depleting substance carbon dioxide, and side effects, such as tires, gas, and different materials.Furthermore, the social effects are the physical outcomes of toxin discharges on general wellbeing (passing, sickness, risks), the wounds and demise coming about because of auto collisions, clamor contamination, the trouble of making virtual excursions without a vehicle or reasonable public vehicle, and other personal satisfaction issues, for example, the loss of open spaces in metropolitan zones because of transport foundation improvements.

All participants state a few issues are disregarded, and hardly any endeavors have been made to decrease them. These include:

- Traffic stream/clog issues brought about by traffic levels, traffic occurrences, deficient street foundation, tight road designs, and helpless driver conduct.

- Transport strategy related issues include disregard of cargo transport issues around and traffic arranging, and other approach issues, such as vehicle access limitations dependent on schedule and size/weight of vehicle and transport paths.

- Parking and stacking/emptying issues, including stacking/emptying guidelines, fines, absence of emptying space, and taking care of issues.

- Customer/beneficiary related issues incorporate lining to make conveyances and assortments, trouble finding the recipient, assortment, and conveyance times mentioned by clients and collectors.

Questions raised after the observation of investing and developing transportation systems around Bangkok. Is that the poor in the area can really benefit?

Is that the quality of life of the people in the area really improve as the concepts and theories have been mentioned?

\section{Conclusion}

Logistic development can be a double-edged sword; the appropriate administration and familiarity with co ordinations exercises' ecological ramifications can essentially lessen the adverse effect. Integrative ecological administration implies that each component in the corporate worth chain is engaged with limiting its full natural effect from beginning to end of the graceful anchor and starting to finish the item life cycle. Directors must reconsider their co ordinations choices to react to impacts originating from different capacities, for example, showcasing and assembling and outside sources, the legislature, and the buyer.

The policymakers should intercede to decrease every one of these effects and the methods for mediation that is generally attractive to create the most practical result in financial, social, and ecological terms.

Transport coordination can work effectively in the long haul if transport and metropolitan arranging accept into account the open doors and potential outcomes of 
cutting edge calculated frameworks in their models. The compensational impacts of progress in coordination must be considered. Extra measures to balance out or recoup stable metropolitan financial structures must be presented. This can be, for example, charges on transport escalated structures. Finally, it needs to be perceived that not all that what is useful for a solitary unit must be useful for the framework.

\section{References}

1. T.R. Lakshmanan, J. of Transport Geography 19(1), 1-12 (2011)

2. B.A. Akhmetzhanoy, Problems of Economic Transition 56(3), 44-48 (2013)

3. World population review, www. worldpopulationreview.com/world-cities/bangkokpopulation

4. Department of Highways, www.westouterringroad.com/about.html

5. M. Př́varová, A. Př́vara, Actual Problems of Economics 10, 324-331 (2015)

6. C.H. Cooley, Publications of the American Economic Association 9, 17-118 (1984)

7. V. Takhumova et al., J. of Applied Economic Sciences 13(7), 1939-1944 (2018)

8. T.R. Ramachandra, J. of Construction in Developing Countries, 49-63 (2013)

9. M. Pitukhina et al., International J. of Ecology \& Development 32(3), 45-52 (2017)

10. N.D. Yu, Transport Reviews 32(1), 3-28 (2012)

11. F. Iyanova, Economics and Management 18(2), 263-274 (2013)

12. D.P. Thomas, J. of Contemporary African Studies, 77-94 (2013)

13. M. Přívarová, A. Př́ivara, International J. of Environmental and Science Education 11(18), 12909-12917 (2016)

14. N. Krasovskaya et al., The EUrASEANs: Journal on Global Socio-Economic Dynamics 5(6), 48-54 (2017)

15. M.B. Givoni, Planning Theory \& Practice 17, 385-404 (2016)

16. N.T. Heeres, Planning Theory \& Practice 17, 421-443 (2016)

17. C. Babb, Planning Theory \& Practice 16, 517-534 (2015)

18. A. Př́vara et al., Migration Letters 16(4), 585-594 (2019) 